\title{
The Relationship between Gait Asymmetry and Respiratory Function in Stroke Patients: A Pilot Study
}

\author{
Yoshino Terui ${ }^{1}$, Satomi Iwasawa ${ }^{2}$, Kazuto Kikuchi ${ }^{3}$, Yutaka Furukawa ${ }^{1,4}$, Eriko Suto², \\ Sachiko Uemura1, Masahiro Satake', Takanobu Shioya1,5 \\ ${ }^{1}$ Department of Rehabilitation, Akita University Graduate School of Health Sciences, Akita City, Akita, Japan \\ ${ }^{2}$ Department of Rehabilitation, Akita Prefectural Center for Rehabilitation and Psychiatric Medicine, Daisen City, Akita, Japan \\ ${ }^{3}$ Department of Physical Therapy, Akita Rehabilitation College, Akita City, Akita, Japan \\ ${ }^{4}$ Department of Rehabilitation Medicine, Akita City Hospital, Akita City, Akita, Japan \\ ${ }^{5}$ Geriatric Health Services Facility Nikoniko-en, Akita City, Akita, Japan \\ Email: terui.akitau.ac@gmail.com
}

How to cite this paper: Terui, Y., Iwasawa, S., Kikuchi, K., Furukawa, Y., Suto, E., Uemura, S., Satake, M. and Shioya, T. (2021) The Relationship between Gait Asymmetry and Respiratory Function in Stroke Patients: A Pilot Study. Open Journal of Therapy and Rehabilitation, 9, 111-122.

https://doi.org/10.4236/ojtr.2021.94009

Received: August 16, 2021

Accepted: September 24, 2021

Published: September 27, 2021

Copyright $\odot 2021$ by author(s) and Scientific Research Publishing Inc. This work is licensed under the Creative Commons Attribution International License (CC BY 4.0).

http://creativecommons.org/licenses/by/4.0/

\begin{abstract}
INTRODUCTION: Gait asymmetry can become very pronounced in patients who have suffered a stroke. The impairment of trunk function in some stroke patients can restrict thorax mobility and cause respiratory muscle weakness. Trunk and neck dysfunction are believed to affect the gait in stroke patients. OBJECTIVE: This study aimed to investigate the relationship between gait asymmetry and respiratory function in stroke patients by measuring the step time and trunk acceleration. METHODS: This study employed a cross-sectional design. Thirty stroke patients participated in this study. The symmetry index (SI) and Lissajous index (LI) were used to evaluate asymmetry during walking. The respiratory function and respiratory muscle strength were evaluated by spirometry. We examined the relation between SI or LI and the respiratory function/respiratory muscle strength in patients with stroke. RESULTS: The results of our analysis demonstrated that the SI was significantly correlated with the inspiratory and expiratory muscle strength and the LI was significantly correlated with the percentage of the predicted vital capacity (respectively, $\mathrm{r}=-0.386, \mathrm{r}=-0.392, \mathrm{r}=-0.446 ; \mathrm{p}<0.05)$. CONCLUSION: The present study is the first to indicate a relationship between gait asymmetry and respiratory function in stroke patients.
\end{abstract}

\section{Keywords}

Gait Asymmetry, Acceleration, Load Meter, Respiratory Function, Stroke 


\section{Introduction}

Gait instability is a common problem in stroke patients [1] [2] [3]. A decrease in gait velocity [4] and gait asymmetry can become very pronounced in patients who have suffered a stroke [5]. Walking with asymmetric step times has substantial metabolic costs beyond those imposed by symmetric step times [5]. Thus, walking efficiency is reduced, and the patient can quickly get tired, making it difficult to extend the walking distance.

The evaluation of gait asymmetry, calculated on the basis of the patient's steps, can be done using time as the measured parameter (temporal asymmetry) or using length (spatial asymmetry). Over $60 \%$ of stroke patients have disability of temporal asymmetry in their gait [6] [7]. In the present study, the symmetry index (SI) was used to evaluate temporal asymmetry in the gait [8]. In addition, gait asymmetry also manifests itself in stroke patients in the movement of the trunk during walking. The Lissajous index (LI) was developed as an evaluation of gait symmetry based on trunk acceleration values [9]. The LI is calculated from the vertical acceleration and medio-lateral acceleration, and hence LI can express any asymmetry in the trunk movement that occurs during walking [9]. The SI is significantly correlated with gait velocity [8]. The LI is significantly correlated with standing balance [9]. In stroke patients, the gait asymmetry is a result of decreases in various physical functions. The symmetry of the swing time is related to the stage of motor recovery in acute stroke [10]. The spasticity of the lower limbs has also been found to affect temporal gait asymmetry in stroke patients [11].

One example of the impairment of trunk function in stroke patients is restricted thorax mobility; this restriction occurs due to the paralysis of one or both upper extremities and to muscle weakness in the trunk, which causes restrictive ventilatory impairment [12]. Previous studies have clarified that stroke patients exhibit weakened respiratory muscle functions [13] [14]. Various studies have investigated training techniques for treating weakness in the respiratory muscles and restricted thorax mobility in stroke patients. Respiratory-muscle training may improve respiratory muscle strength in patients with neurological conditions, including stroke patients [15] [16]. In stroke patients, the trunk function as evaluated using the Trunk Impairment Scale was significantly correlated with the respiratory functions and respiratory muscle strength [17]. However, a relationship between respiratory function and gait asymmetry in stroke patients has not been established.

As previously indicated, the decrease in respiratory function in stroke patients is caused by the restriction of thorax mobility and low respiratory muscle strength. It was expected that gait asymmetry was affected by muscle strength and by the alignment of the trunk and shoulder girdle. Therefore, we conducted the present study to investigate the relationship between gait asymmetry and respiratory function in stroke patients. 


\section{Materials and Methods}

\subsection{Study Design}

This study is a cross-sectional study. All patients underwent a 10-m walk test so that definitive step time and trunk acceleration data during walking could be recorded, and all patients also underwent a respiratory function test and respiratory muscle strength assessment. This study was reviewed and approved by the Ethics Committees of Akita University Graduate School of Medicine (No. 1319) and Akita Prefectural Center for Rehabilitation and Psychiatric Medicine (No. 127) and was carried out according to the Declaration of Helsinki. Written consent was obtained from all participants.

\subsection{Participants}

Thirty patients with an initial stroke event and hemiplegia (19 males; ages $61 \pm 11$ years) who had undergone stroke rehabilitation at Akita Prefectural Center for Rehabilitation and Psychiatric Medicine were enrolled in this study. The following patients were excluded: 1) patients who were not able to walk by themselves without support; 2) patients with an illness or injury other than stroke that impaired their behavior; 3) patients who had ataxia due to stroke; and 4) patients who did not understand the purpose of the experiment. Figure 1 shows the flow of patient selection. The characteristics of the patients are summarized in Table 1.

Power analysis was performed using the program $G^{\star}$ Power 3.1; a correlation analysis was performed with an $\alpha$ of 0.05 , a power of 0.80 , and an expected correlation between the trunk balance and the respiratory function/respiratory muscle strength of 0.5 .11 . The calculated sample size in the power analysis was 28.

Table 1. Demographics of the participants $(n=30)$.

\begin{tabular}{cc}
\hline Variables & Stroke patients \\
\hline Age (years) & $61(11)$ \\
Height $(\mathrm{cm})$ & $161.2(8.9)$ \\
Weight $(\mathrm{kg})$ & $57.4(9.0)$ \\
BMI $\left(\mathrm{kg} / \mathrm{m}^{2}\right)$ & $22.0(2.7)$ \\
Disease duration (days) & $96.0(44.7)$ \\
Clinical entity (n) & $21 / 9$ \\
Hemorrhage/infraction & $17 / 13$ \\
Paralyzed side (n) & \\
Right/left & $4(3,5)$ \\
SIAS, Hip & $4(1,5)$ \\
SIAS, Knee & $3(0,5)$ \\
SIAS, Ankle &
\end{tabular}

Definitions: BMI; body mass index, SIAS; Stroke Impairment Assessment Set. Data are presented as mean (SD) or median (minimum, maximum) unless otherwise indicated. 


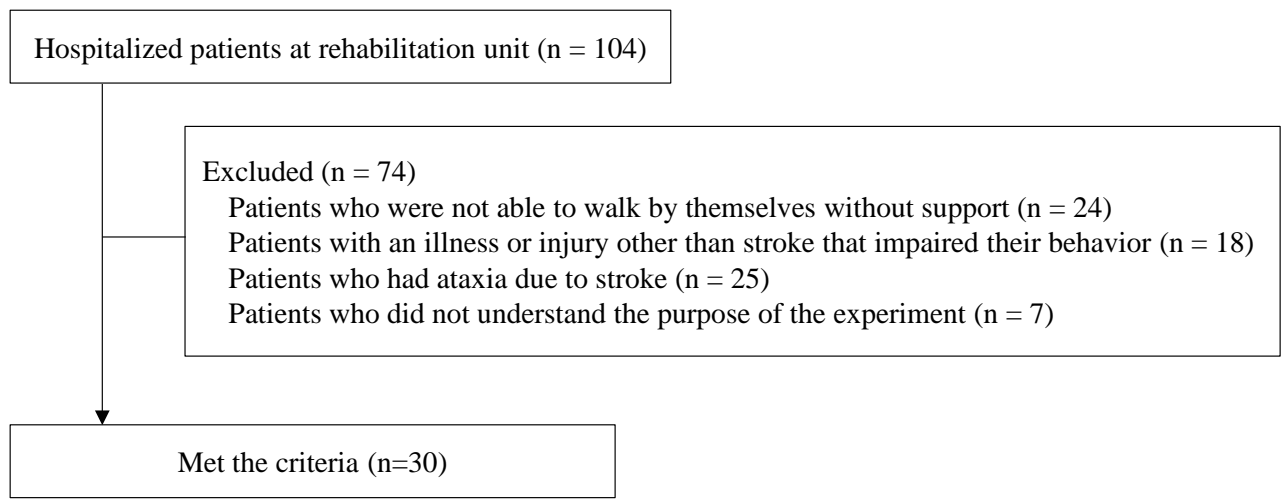

Figure 1. Flowchart of patients with stroke included in this study.

\subsection{Measurement of Step Time and SI}

To measure the step time, a load meter (MP-1000, Anima, Tokyo) was used. The MP-1000 is a wireless sensor that can be placed inside of shoes. The MP-1000 was used to calculate the step time, standing time, and the percentage of the weight load on each lower limb. We used the step time to calculate the SI [8] according to the following formula:

$$
\mathrm{SI}=\frac{V_{\text {paratic }}-V_{\text {nonparatic }}}{1 / 2\left(V_{\text {paratic }}-V_{\text {nonparatic }}\right)} \times 100
$$

$V_{\text {paratic }}=$ step time of a paratic limb, $V_{\text {nonparatic }}=$ step time of a nonparatic limb

We used the absolute value of the SI to evaluate the extent of the asymmetry. A high SI value indicates asymmetry, and a low SI value denotes symmetry [8].

\subsection{Asymmetry of Trunk Acceleration}

\subsubsection{Tri-Axial Accelerometer}

A wireless tri-axial accelerometer (MG-M1110; LSI Medience, Tokyo) [18] [19] was used. This accelerometer was $75 \mathrm{~mm}$ long $\times 20 \mathrm{~mm}$ wide $\times 50 \mathrm{~mm}$ high; it weighed $120 \mathrm{~g}$. The sampling rate was $100 \mathrm{~Hz}$. The accelerometer was used to measure the vertical, anteroposterior, and mediolateral acceleration of the trunk during walking. Each aspect of acceleration was represented on graphs produced by the analysis software on a personal computer (MG-M1110-PC ${ }^{\mathrm{TM}}$; LSI Medience, Tokyo) [18] [19]. This software calculated the steps, gait speed, and gait coefficient of variation and exported the values of each aspect of acceleration into Microsoft Excel (Excel).

\subsubsection{Accelerometry Procedures}

The accelerometer was fixed to a belt at the level of the patient's L3 spinous process. Each patient performed a 10 -m walk test twice so that definitive trunk acceleration data could be recorded. A 10-m-long walkway with 1-m spare walkway areas at both the starting and ending points was constructed. For the walk test, the patient was instructed to walk straight at a self-selected comfortable speed toward a target line on the floor. 


\subsubsection{Method for Making Lissajous Figure}

All acceleration data from the 10-m walk were used except for those from the patient's first and final steps. Using Excel, we plotted the Lissajous figure (LF) on a scatter chart with the $y$-axis representing the vertical acceleration and the $x$ axis representing the mediolateral acceleration [9]. Figure 2 shows the LF made from the measured trunk acceleration values in a representative patient.

\subsubsection{Calculation of the LI}

As shown in Figure 2, the areas that were calculated for the LI were a quadrangle surrounded by an undulating line $\left(R_{r}\right)$ and a quadrangle surrounded by an undulating and dotted line $\left(R_{l}\right)$. The formula for calculating the LI was as follows:

$$
\mathrm{LI}=\left|\frac{2 \times\left(R_{r}-R_{l}\right)}{\left(R_{r}+R_{l}\right)}\right| \times 100
$$

A high LI value indicates asymmetry, and a low LI value denotes symmetry on the frontal plane [9].

\subsection{Respiratory Function/Respiratory Muscle Strength}

The patients' pulmonary function was assessed using three parameters: the vital capacity $(\mathrm{VC})$, forced expiratory volume in 1 second $\left(\mathrm{FEV}_{1}\right)$, and the $\mathrm{FEV}_{1} /$ forced VC. These parameters were measured using a spirometer (Autospiro AS507, Minato Medical Science, Osaka, Japan). The VC and $\mathrm{FEV}_{1}$ were expressed as percentages of the predicted values derived from Kubota et al. (\%VC and $\left.\% \mathrm{FEV}_{1}\right)$ [20]. The maximal inspiratory mouth pressure (PImax) and the maximal expiratory mouth pressure (PEmax) were measured to represent respiratory muscle

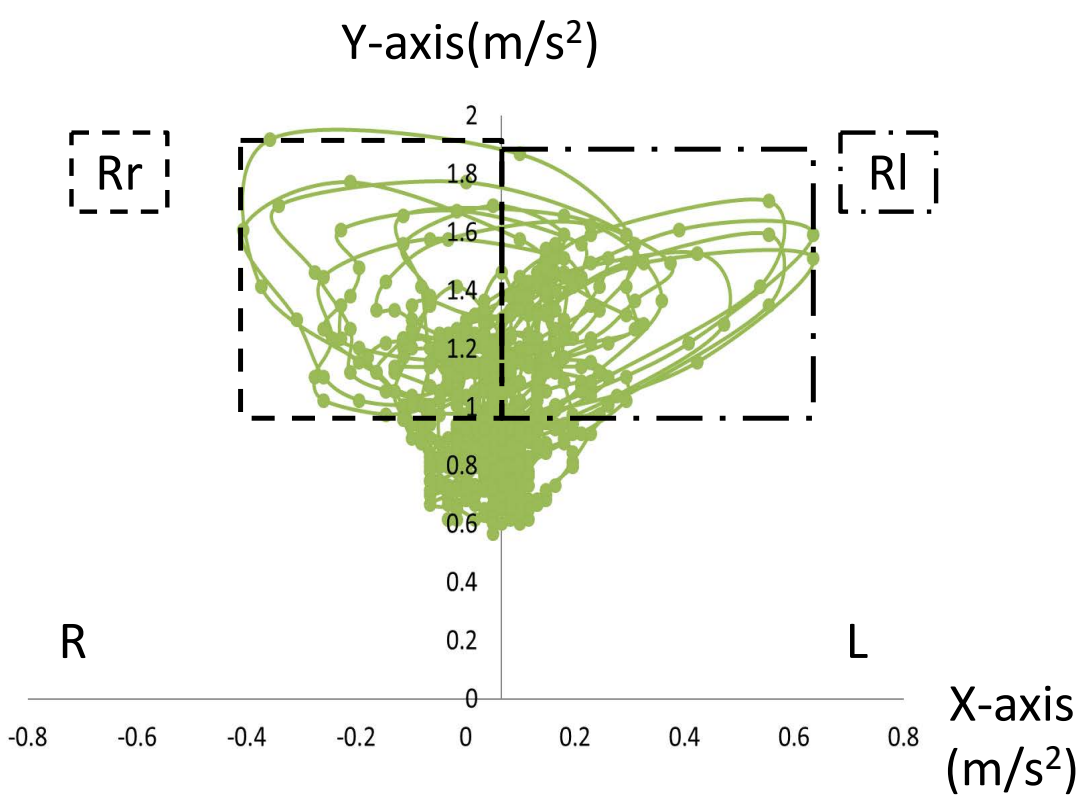

Figure 2. Lissajous figure. $R_{r}$ : Right quadrangle surrounded by undulating line; $R_{t}$. Left quadrangle surrounded by undulating and dot line; R; right side, L; left side. 
strength using the Autospiro AS-507 spirometer following the method recommended by the American Thoracic Society/European Respiratory Society [21]. The values were expressed as percentages of the predicted values derived from Suzuki et al. [22] (\%PImax and \%PEmax).

\subsection{Statistical Analysis}

The assumption of normality was assessed using the Shapiro-Wilk test. We used Spearman's rank correlation coefficient to identify the respiratory function/respiratory muscle strength level that had an effect on the absolute value of the SI and the LI of the stroke patients. SPSS Statistics 24 (IBM, Armonk, NY) was used for the statistical analyses (level of significance $\mathrm{p}<0.05$ ).

\section{Results}

The mean absolute value of the SI was $19.7 \pm 16.3$ (Table 2). Figure 3 illustrates the actual LF of patients with stroke. The mean LI value was $43.4 \% \pm 33.2 \%$ (Table 2). The mean \%VC value of the 30 stroke patients was $87.0 \% \pm 15.3 \%$ and the mean $\% \mathrm{FEV}_{1}$ value was $79.6 \% \pm 25.7 \%$ (Table 2 ). The other respiratory function and respiratory muscle strength values of the patients were also smaller than the respective predicted values (Table 2 ). The results of our analysis demonstrated that the absolute value of the SI was significantly correlated with \%PImax and \%PEmax, and the LI was significantly correlated with \%VC in this series of stroke patients (respectively, $\mathrm{r}=-0.386, \mathrm{p}=0.042, \mathrm{r}=-0.392, \mathrm{p}=0.047$ and $\mathrm{r}=-0.446, \mathrm{p}=0.023$ ) (Table 3 ).

\section{Discussion}

In this study, the mean absolute value of SI was found to be 19.7. In a previous study, the mean absolute value of SI was 17.3 [8]. In our previous study, the mean LI of the healthy subjects was $21.1 \%$, [9] and in the present study the mean

Table 2. Gait asymmetry and Respiratory function/muscle strength data.

\begin{tabular}{cc}
\hline Variation & \\
\hline SI & $19.7(16.3)$ \\
LI (\%) & $43.3(33.2)$ \\
\%VC (\%) & $87.0(15.3)$ \\
\%FEV $(\%)$ & $79.6(25.7)$ \\
FEV $/$ FVC (\%) & $82.8(16.0)$ \\
\%PImax (\%) & $47.9(26.9)$ \\
\%PEmax (\%) & $44.8(18.8)$
\end{tabular}

Definitions: SI; Symmetry Index (absolute value), LI; Lissajous Index, VC; vital capacity, $\mathrm{FEV}_{1}$; forced expiratory volume in 1 second, FVC; forced vital capacity, PImax; maximal inspiratory mouth pressure, PEmax; maximal expiratory mouth pressure. Data are presented as mean (SD). 


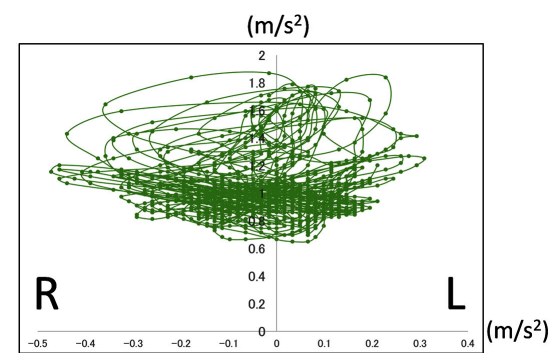

(a)

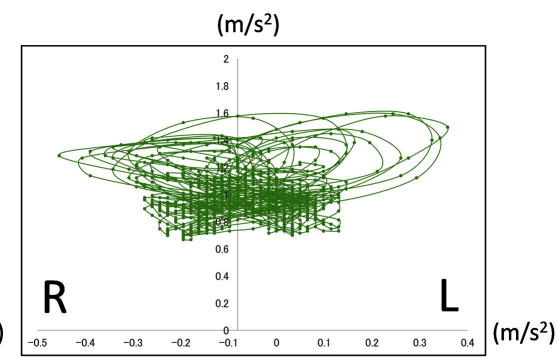

(b)

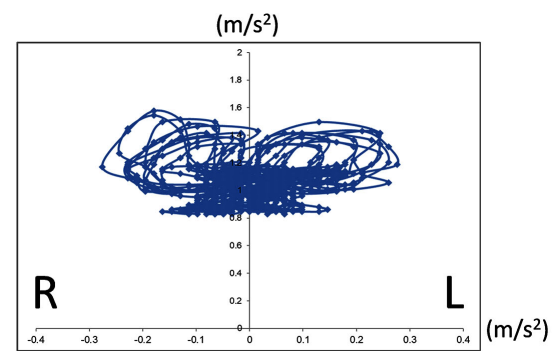

(c)

Figure 3. Actual Lissajous Figures. (a) Lissajous figure of the female patient (49 years old) with left side paresis. The area of right side is larger than that of left side; (b) Lissajous figure of the female patient (70 years old) with right side paresis. The area of left side is larger than that of right side; (c) Lissjous figure of female healthy subject (65 years old) was illustrated by an example. R; right side, L; left side.

Table 3. Correlation between gait asymmetry and respiratory function/muscle strength.

\begin{tabular}{ccc}
\hline Variation & SI (r) & LI (r) \\
\hline \%VC (\%) & -0.299 & $-0.446^{*}$ \\
\%FEV $1 \%)$ & -0.327 & -0.195 \\
FEV $_{1} /$ FVC (\%) & -0.130 & 0.176 \\
\%PImax (\%) & $-0.386^{*}$ & -0.237 \\
\%PEmax (\%) & $-0.392^{*}$ & -0.224 \\
\hline
\end{tabular}

Definitions: SI; Symmetry Index (absolute value), LI; Lissajous Index, VC; vital capacity, $\mathrm{FEV}_{1}$; forced expiratory volume in 1 second, FVC; forced vital capacity, PImax; maximal inspiratory mouth pressure, PEmax; maximal expiratory mouth pressure. ${ }^{*} ; \mathrm{p}<0.05$.

LI of the stroke patients was $43.4 \%$, which is much higher than the LI of the healthy subjects. The patients in this study showed a dominantly asymmetrical gait both in terms of their steps and their trunk movement. The stroke patients had various severity of lower limbs and various gait abnormality. Thus, the standard deviation of LI and SI became large. In the future, the stroke patients are divided into degree of severity of groups and investigated gait asymmetry.

The mean \%VC and $\% \mathrm{FEV}_{1}$ values and the respiratory muscle strength values were all low in the present stroke patients. However, these patients did not have restrictive ventilatory impairment because their $\%$ VC values were $>80 \%$. They were all able to walk $10 \mathrm{~m}$ without a cane, and 15 patients walked independently. Stroke patients with heavy hemiparesis were not included in this study. In other investigations, the muscle-strength level of stroke patients was weak, [23] [24] [25] [26] [27] and this weakness was also observed in the present patients.

In the present study, the participants who had lower respiratory muscle strength showed more temporal asymmetry in their gait, while the participants who had lower VC values showed more asymmetry in their trunk movement while walking. The legs of stroke patients may suffer from paralysis or spasticity, and it has become clear that the trunk may also be affected by stroke-induced ambulatory disability [28] [29]. There is evidence that trunk training can improve the trunk control, standing balance, and mobility of individuals who have experienced a 
stroke [30]. In this study, both the inspiratory and expiratory muscles were significantly correlated with temporal asymmetry during walking in stroke patients. The inspiratory muscles include muscles in the neck region and the muscles surrounding the thorax. The expiratory muscles include the muscles of the lower trunk. There is a relationship between the SI and gait speed in stroke patients [8]. Therefore, the muscle strength from the neck region to the trunk is related to gait asymmetry and ambulatory ability.

In this study, asymmetry in trunk movement during walking was significantly correlated with \%VC. The participants did not have respiratory diseases; thus, degradation of the \% $\mathrm{VC}$ occurred due to restriction of the thorax movement. Respiratory muscle stretching in post-stroke patients with hemiparesis demonstrated that the acute effects of such stretching can contribute to the expansion of the respiratory system during tidal breathing [31]. Voyvoda et al. reported a decrease in the movement of the diaphragm during deep breathing in hemiplegic patients [32]. Herein, we calculated the LI values of the stroke patients based on their trunk acceleration, measured by an accelerometer attached to the patient's back at the lower lumbar spine (L3). Thus, the LI was affected not only by the movement of the patient's lower extremities but also by the movement of his or her trunk. In addition, we observed in a previous investigation that the LI was significantly correlated with the Berg Balance Scale [9] which evaluates a subject's standing balance, and standing balance is related to the trunk function [33] [34] [35]. The diaphragm has properties related to the maintenance of lumbar spinal stability [36] [37] [38] [39]. The relationship that we observed herein between the \%VC and the LI is thus based on a common denominator, i.e., the impairment of the trunk function.

There are a few limitations to the present study. First, the patients in this study included both patients with mild impairment and patients with moderate impairment. To investigate the relationship between gait asymmetry and respiratory function/muscle strength in more detail, the patients should be classified according to severity. Second, the present study was not a longitudinal study. In the future, it will be necessary to determine whether improvement of the respiratory function/respiratory muscle strength is related to an improvement in gait asymmetry.

\section{Conclusion}

The present study is the first to examine the relationship between gait asymmetry and respiratory function in stroke patients. The results of our analyses demonstrated that temporal asymmetry as evaluated using the SI was significantly correlated with the strength of the respiratory muscles. These results also showed that gait asymmetry in the trunk movement was significantly correlated with \%VC values in stroke patients. Weakness in the neck and trunk muscles was related to gait asymmetry in stroke patients. The restriction of thorax mobility in these patients, reflected by a decrease in their lung capacity, was related to the limitation of their trunk movement during walking. 


\section{Acknowledgements}

We would like to thank all staff members of the department of Rehabilitation, Akita Prefectural Center for Rehabilitation and Psychiatric Medicine, for their help. This work was supported by JSPS KAKENHI Grant Number JP19K19864.

\section{Funding}

This research was funded by JSPS KAKENHI Grant Number JP19K19864.

\section{Conflicts of Interest}

The authors declare no conflicts of interest regarding the publication of this paper.

\section{References}

[1] Belda-Lois, J.M., Mena-del, H.S., Bermejo-Bosch, I., Moreno, J.C., Pons, J.L., Farina, D., et al. (2011) Rehabilitation of Gait after Stroke: A Review towards a Top-Down Approach. Journal of NeuroEngineering and Rehabilitation, 8, Article No. 66. https://jneuroengrehab.biomedcentral.com/articles/10.1186/1743-0003-8-66 https://doi.org/10.1186/1743-0003-8-66

[2] Anastasi, D., Carpinella, I., Gervasoni, E., Matsuda, P.N., Bovi, G., Ferrarin, M., et al. (2019) Instrumented Version of the Modified Dynamic Gait Index in Patients with Neurologic Disorder. PMR, 11, 1312-1319. https://doi.org/10.1002/pmrj.12137

[3] Kimura, T. (2021) Interaction between Self-Care and Caregiving Ability on Home Discharged Stroke Patients Based on Motor Functional Independence Measure Score in Recovery Ward. Open Journal of Therapy and Rehabilitation, 9, 42-56. https://scirp.org/journal/paperinformation.aspx?paperid=108214 https://doi.org/10.4236/ojtr.2021.92004

[4] Sheffler, L.R. and Chae, J. (2015) Hemiparetic Gait. Physical Medicine and Rehabilitation Clinics of North America, 26, 611-623.

https://www.sciencedirect.com/science/article/abs/pii/S1047965115000534?via\%3Di $\underline{\text { hub }}$ https://doi.org/10.1016/j.pmr.2015.06.006

[5] Ellis, R.G., Howard, K.C. and Kram, R. (2013) The Metabolic and Mechanical Costs of Step Time Asymmetry in Walking. Proceedings. Biological Sciences, 280, Article ID: 20122784. https://www.ncbi.nlm.nih.gov/pmc/articles/PMC3574372 https://doi.org/10.1098/rspb.2012.2784

[6] Patterson, K.K., Gage, W.H., Brooks, D., Black, S.E. and Mcllroy, W.E. (2010) Evaluation of Gait Symmetry after Stroke: A Comparison of Current Methods and Recommendations for Standardization. Gait Posture, 31, 241-246.

https://www.sciencedirect.com/science/article/pii/S0966636209006493?via\%3Dihub https://doi.org/10.1016/j.gaitpost.2009.10.014

[7] Patterson, K.K., Parafianowicz, I., Danells, C.J., Closson, V., Verrier, M.C., Staines, W.R., et al. (2008) Gait Asymmetry in Community-Ambulating Stroke Survivors. Archives of Physical Medicine and Rehabilitation, 89, 304-310. https://www.sciencedirect.com/science/article/pii/S0003999307016498?via\%3Dihub https://doi.org/10.1016/j.apmr.2007.08.142

[8] Kim, C.M. and Eng, J.J. (2003) Symmetry in Vertical Ground Reaction Force Is Ac- 
companied by Symmetry in Temporal But Not Distance Variables of Gait in Persons with Stroke. Gait Posture, 18, 23-28.

https://doi.org/10.1016/S0966-6362(02)00122-4

https://www.sciencedirect.com/science/article/pii/S0966636202001224?via\%3Dihub

[9] Terui, Y., Suto, E., Konno, Y., Kubota, K., Iwakura, M., Satou, M., et al. (2018) Evaluation of Gait Symmetry Using a Tri-Axial Accelerometer in Stroke Patients. NeuroRehabilitation, 42, 173-180. https://doi.org/10.3233/NRE-172235

https://content.iospress.com/articles/neurorehabilitation/nre172235

[10] Brandstater, M.E., de Bruin, H., Gowland, C. and Clark, B.M. (1983) Hemiplegic Gait: Analysis of Temporal Variables. Archives of Physical Medicine and Rehabilitation, 64, 583-587.

[11] Yang, Y.R., Mi, P.L., Huang, S.F., Chiu, S.L., Liu, Y.C. and Wang, R.Y. (2018) Effects of Neuromuscular Electrical Stimulation on Gait Performance in Chronic Stroke with Inadequate Ankle Control-A Randomized Controlled Trial. PLoS ONE, 13, e0208609. https://doi.org/10.1371/journal.pone.0208609

https://journals.plos.org/plosone/article?id=10.1371/journal.pone.0208609

[12] Fugl-Meyer, A.R., Linderholm, H. and Wilson, A.F. (1983) Restrictive Ventilatory Dysfunction in Stroke: Its Relation to Locomotor Function. Scandinavian Journal of Rehabilitation Medicine. Supplement, 9, 118-124.

[13] Xiao, Y., Luo, M., Wang, J. and Luo, H. (2012) Inspiratory Muscle Training for the Recovery of Function after Stroke. Cochrane Database of Systematic Reviews, No. 5, CD009360. https://doi.org/10.1002/14651858.CD009360.pub2

[14] Billinger, S.A., Coughenour, E., Mackay-Lyons, M.J. and Ivey, F.M. (2012) Reduced Cardiorespiratory Fitness after Stroke: Biological Consequences and Exercise-Induced Adaptations. Stroke Research and Treatment, 2012, Article ID: 959120.

https://www.ncbi.nlm.nih.gov/pmc/articles/PMC3159380 https://doi.org/10.1155/2012/959120

[15] Pollock, R.D., Rafferty, G.F., Moxham, J. and Kalra, L. (2013) Respiratory Muscle Strength and Training in Stroke and Neurology: A Systematic Review. International Journal of Stroke, 8, 124-130. https://doi.org/10.1111/j.1747-4949.2012.00811.x

[16] Messaggi-Sartor, M., Guillen-Solà, A., Depolo, M., Duarte, E., Rodríguez, D.A., Barrera, M.C., et al. (2015) Inspiratory and Expiratory Muscle Training in Subacute Stroke: A Randomized Clinical Trial. Neurology, 85, 564-572.

https://n.neurology.org/content/85/7/564.long https://doi.org/10.1212/WNL.0000000000001827

[17] Lee, K., Cho, J.E., Hwang, D.Y. and Lee, W. (2018) Decreased Respiratory Muscle Function Is Associated with Impaired Trunk Balance among Chronic Stroke Patients: A Cross-Sectional Study. The Tohoku Journal of Experimental Medicine, 245, 79-88. https://www.jstage.jst.go.jp/article/tjem/245/2/245 79/ article/-char/ja https://doi.org/10.1620/tjem.245.79

[18] Yoneyama, M., Mitoma, H. and Okuma, Y. (2013) Accelerometry-Based Long-Term Monitoring of Movement Disorders: From Diurnal Gait Behavior to Nocturnal Bed Mobility. Journal of Mechanics in Medicine and Biology, 13, Article ID: 1350041. https://doi.org/10.1142/S0219519413500413

[19] Yoneyama, M., Kurihara, Y., Watanabe, K. and Mitoma, H. (2013) Accelerometry-Based Gait Analysis and Its Application to Parkinson's Disease Assessment Part 2: A New Measure for Quantifying Walking Behavior. IEEE Transactions on Neural Systems and Rehabilitation Engineering, 21, 999-1005.

https://ieeexplore.ieee.org/document/6542732 
https://doi.org/10.1109/TNSRE.2013.2268251

[20] Kubota, M., Kobayashi, H., Quanjer, P.H., Omori, H., Tatsumi, K. and Kanazawa, M. (2014) Reference Values for Spirometry, Including Vital Capacity, in Japanese Adults Calculated with the LMS Method and Compared with Previous Values. Respiratory Investigation, 52, 242-250. https://doi.org/10.1016/j.resinv.2014.03.003 https://www.sciencedirect.com/science/article/pii/S2212534514000288?via\%3Dihub

[21] American Thoracic Society/European Respiratory Society (2002) ATS/ERS Statement on Respiratory Muscle Testing. American Journal of Respiratory and Critical Care Medicine, 166, 518-624. https://doi.org/10.1164/rccm.166.4.518

[22] Suzuki, M., Teramoto, S., Sudo, E., Ogawa, K., Namekawa, T., Motrita, K., et al. (1997) Age-Related Changes in Static Maximal Inspiratory and Expiratory Pressures. $\mathrm{Ni}$ hon Kyobu Shikkan Gakkai Zasshi, 35, 1305-1311.

[23] Joo, S., Shin, D. and Song, C. (2015) The Effects of Game-Based Breathing Exercise on Pulmonary Function in Stroke Patients: A Preliminary Study. Medical Science Monitor, 21, 1806-1811. https://doi.org/10.12659/MSM.893420 https://www.medscimonit.com/abstract/index/idArt/893420

[24] Kim, C.Y., Lee, J.S., Kim, H.D. and Kim, I.S. (2015) Effects of the Combination of Respiratory Muscle Training and Abdominal Drawing-In Maneuver on Respiratory Muscle Activity in Patients with Post-Stroke Hemiplegia: A Pilot Randomized Controlled Trial. Topics in Stroke Rehabilitation, 22, 262-270.

https://doi.org/10.1179/1074935714Z.0000000020

[25] Seo, K.C., Lee, H.M. and Kim, H.A. (2013) The Effects of Combination of Inspiratory Diaphragm Exercise and Expiratory Pursed-Lip Breathing Exercise on Pulmonary Functions of Stroke Patients. The Journal of Physical Therapy Science, 25, 241 244. https://doi.org/10.1589/jpts.25.241 https://www.jstage.jst.go.jp/article/jpts/25/3/25 JPTS-2012-282/ article/-char/ja

[26] Sutbeyaz, S.T., Koseoglu, F., Inan, L. and Coskun, O. (2010) Respiratory Muscle Training Improves Cardiopulmonary Function and Exercise Tolerance in Subjects with Subacute Stroke: A Randomized Controlled Trial. Clinical Rehabilitation, 24, 240-250. https://doi.org/10.1177/0269215509358932

[27] Oh, D.S. and Park, S.E. (2016) The Effect of Lumbar Stabilization Exercise on the Pulmonary Function of Stroke Patients. The Journal of Physical Therapy Science, 28, 1896-1900. https://doi.org/10.1589/jpts.28.1896 https://www.jstage.jst.go.jp/article/jpts/28/6/28 jpts-2016-139/_pdf/-char/en

[28] De Quervain, I.A., Simon, S.R., Leurgans, S., Pease, W.S. and McAllister, D. (1996) Gait Pattern in the Early Recovery Period after Stroke. The Journal of Bone and Joint Surgery. American Volume, 78, 1506-1514.

https://journals.lww.com/jbjsjournal/Abstract/1996/10000/Gait Pattern in the Ear ly Recovery Period after.8.aspx https://doi.org/10.2106/00004623-199610000-00008

[29] Tyson, S.F. (1999) Trunk Kinematics in Hemiplegic Gait and the Effect of Walking Aids. Clinical Rehabilitation, 13, 295-300. https://doi.org/10.1191/026921599666307333

[30] Van Criekinge, T., Truijen, S., Schröder, J., Maebe, Z., Blanckaert, K., van der Waal, C., et al. (2019) The Effectiveness of Trunk Training on Trunk Control, Sitting and Standing Balance and Mobility Post-Stroke: A Systematic Review and Meta-Analysis. Clinical Rehabilitation, 33, 992-1002. https://doi.org/10.1177/0269215519830159

[31] Rattes, C., Campos, S.L., Morais, C., Gonçalves, T., Sayão, L.B., Galindo-Filho, V.C., 
et al. (2018) Respiratory Muscles Stretching Acutely Increases Expansion in Hemiparetic Chest Wall. Respiratory Physiology \& Neurobiology, 254, 16-22.

https://www.sciencedirect.com/science/article/pii/S1569904817303890?via\%3Dihub https://doi.org/10.1016/j.resp.2018.03.015

[32] Voyvoda, N., Yücel, C., Karatas, G., Oguzülgen, I. and Oktar, S. (2012) An Evaluation of Diaphragmatic Movements in Hemiplegic Patients. The British Journal of Radiology, 85, 411-414. https://www.ncbi.nlm.nih.gov/pmc/articles/PMC3485549 https://doi.org/10.1259/bjr/71968119

[33] Cabanas-Valdés, R., Bagur-Calafat, C., Girabent-Farrés, M., Caballero-Gómez, F.M., du Port de Pontcharra-Serra, H., German-Romero, A., et al. (2017) Long-Term Follow-Up of a Randomized Controlled Trial on Additional Core Stability Exercises Training for Improving Dynamic Sitting Balance and Trunk Control in Stroke Patients. Clinical Rehabilitation, 31, 1492-1499. https://doi.org/10.1177/0269215517701804

[34] Cabanas-Valdés, R., Bagur-Calafat, C., Girabent-Farrés, M., Caballero-Gómez, F.M., Hernández-Valiño, M. and Urrútia Cuchí, G. (2016) The Effect of Additional Core Stability Exercises on Improving Dynamic Sitting Balance and Trunk Control for Subacute Stroke Patients: A Randomized Controlled Trial. Clinical Rehabilitation, 30, 1024-1033. https://doi.org/10.1177/0269215515609414

[35] Souza, D.C.B., de Sales Santos, M., da Silva Ribeiro, N.M. and Maldonado, I.L. (2019) Inpatient Trunk Exercises after Recent Stroke: An Update Meta-Analysis of Randomized Controlled Trials. NeuroRehabilitation, 44, 369-377.

https://content.iospress.com/articles/neurorehabilitation/nre182585 https://doi.org/10.3233/NRE-182585

[36] Kocjan, J., Gzik-Zroska, B., Nowakowska, K., Burkacki, M., Suchoń, S., Michnik, R., et al. (2018) Impact of Diaphragm Function Parameters on Balance Maintenance. PLoS ONE, 13, e0208697. https://doi.org/10.1371/journal.pone.0208697 https://journals.plos.org/plosone/article?id=10.1371/journal.pone.0208697

[37] Bordoni, B., Marelli, F. and Bordoni, G. (2016) A Review of Analgesic and Emotive Breathing: A Multidisciplinary Approach. Journal of Multidisciplinary Healthcare, 9 , 97-102. https://www.ncbi.nlm.nih.gov/pmc/articles/PMC4778783 https://doi.org/10.2147/JMDH.S101208

[38] Hodges, P.W. and Gandevia, S.C. (2000) Activation of the Human Diaphragm during a Repetitive Postural Task. The Journal of Physiology, 522, 165-175. https://doi.org/10.1111/j.1469-7793.2000.t01-1-00165.xm

[39] Hodges, P.W., Heijnen, I. and Gandevia, S.C. (2001) Postural Activity of the Diaphragm Is Reduced in Humans When Respiratory Demand Increases. The Journal of Physiology, 537, 999-1008. https://doi.org/10.1113/jphysiol.2001.012648 